\title{
A postura no trabalho dos operadores de checkout de supermercados: uma necessidade constante de análises
}

\author{
Eduardo Concepción Batiz SOCIESC \\ Andréia Fuentes dos Santos UNIPAR \\ Olga Elena Anzardo Licea
}

\section{RESUMO}

As condições de trabalho nas quais os operadores de checkout de supermercados realizam suas atividades têm sido uma preocupação dos especialistas nos últimos tempos. Essa pesquisa foi realizada em oito supermercados de duas cidades do Brasil com o objetivo de conhecer as condições em que os operadores realizam suas atividades, detectando os fatores de risco para propor medidas que eliminem ou minimizem o aparecimento de efeitos adversos nos trabalhadores. Foi aplicado um questionário e o método RULA a uma amostra de 80 trabalhadores. 0 estudo mostrou que o mobiliário não está adaptado às características antropométricas da população, a maioria das posturas analisadas é inadequada, não existem revezamento nem pausas que poderiam ajudar a minimizar a situação, existência de sobrecarga, mental e física, entre outras. Conclui-se que a atividade pode representar riscos à saúde dos operadores de caixa de supermercados.

\section{PALAVRAS-CHAVE}

Checkout, riscos, ergonomia.

\section{Supermarket checkout operators posture at work: The continuous need for analysis}

\begin{abstract}
The work conditions in which supermarket checkout operators perform activities have been a recent concern to specialists. This research was carried out in eight supermarkets of two cities in Brazil with the aim of knowing the conditions under which operators work, in order to detect risk factors and to propose procedures that could eliminate or minimize their adverse effects on workers. Structured questionnaire and the RULA method was applied to a sample of 80 workers. Major findings of the study as follows: furniture was not adapted to anthropometric characteristics of the workers, most of analyzed positions are not adequate, there was no rotation or pauses that could reduce the risk, there was a significant amount of mental and physical work overload. We conclude that, under current conditions, checkout operations at supermarkets poses health risk to operators.
\end{abstract}

\section{KEY WORDS}

Checkout, risks, ergonomics. 


\section{INTRODUÇÃO}

Atualmente o ser humano passa uma parte importante de sua vida no ambiente laboral, realizando diferente atividades o que demanda que as condições de trabalho sejam adequadas para evitar que existam riscos que possam provocar acidentes de trabalho e alterações à saúde dos trabalhadores.

Um trabalhador será mais produtivo na medida em que esteja satisfeito e motivado no trabalho, e essa satisfação e motivação dependem em grande medida das condições de trabalho em que ele desenvolve suas atividades e da forma como ele participa na busca e solução dos problemas, existindo uma relação direta e estreita entre produtividade, satisfação e motivação.

Deve ser interesse de todos que sejam realizadas melhorias constantes nas condições de trabalho para que este possa ser realizado de tal maneira que as cargas provenientes da atividade não ultrapassem os limites fisiológicos do trabalhador, assim como não causem problemas à saúde. Desta forma, observar-se-á maior motivação e satisfação do trabalhador.

Para a "melhoria das condições de trabalho, tanto de forma corretiva - melhorias em sistemas já existentes - quanto de maneira prospectiva - melhorias nos sistemas de trabalho em fase de concepção e projeto -, é necessário avaliar o trabalho humano existente, por critérios bem definidos, aceitos e que obedeçam a uma hierarquia de níveis de valoração relacionados com o trabalhador" (SELL, I., 1995).

Quando os elementos que distinguem as condições de trabalho (condições técnicas: características dos instrumentos, máquinas, ambiente do posto de trabalho, etc.; condições organizacionais: procedimentos prescritos, ritmos impostos, conteúdo do trabalho; condições subjetivas características do operador: saúde, idade, formação; condições sociais: remuneração, qualificação, vantagens sociais, segurança de emprego, em certos casos condições de alojamento e de transporte, relações com a hierarquia, etc.) (MONTMOLLIN, M., 1997) são adequados, pode-se dizer que as condições de trabalho também são adequadas e, por consequência, os trabalhadores poderão realizar suas atividades em um ambiente que não produza riscos de danos a sua saúde.

Um elemento importante dentro das condições de trabalho é sem dúvida a organização, que é a definição das tarefas e das condições de execução, por instâncias exteriores aos trabalhadores (DEJOURS, C., 1991). Dentro do ponto de vista ergonômico, a organização do trabalho tem como objetivos a concepção e o planejamento do trabalho (definição e repartição de funções, tarefas e postos de trabalho), a implantação dos meios de trabalho (espaços, máquinas, lo- gística, recursos humanos) e controle e avaliação do trabalho (planificação e ação, coordenação e regulação, avaliação do alcance dos objetivos).

Com o objetivo de conhecer as reais condições em que atualmente o trabalhador realiza suas atividades, a ergonomia, seja ela análise de correção, projeto das condições de trabalho, ou de análise prospectiva, o importante é que garanta ao trabalhador o mínimo de riscos à saúde durante o desenvolvimento das suas atividades.

A Ergonomia se constitui como uma ciência aplicada capaz de adaptar as condições de trabalho às capacidades psicofisiológicas do trabalhador. É definida como um conjunto de conhecimentos científicos relativos ao homem e necessários à concepção de instrumentos, dispositivos, materiais que possam ser utilizados com o máximo de conforto, segurança e eficácia pelas pessoas (WISNER, A., 1994).

\section{posto de trabalho dos operadores de caixa de supermercado é um exemplo da sidade de mudanças.}

O ambiente laboral está formado por todos aqueles fatores que de forma objetiva influenciam o trabalhador e na medida em que esses fatores forem adequados, melhor será o comportamento do organismo humano frente a essas condições, portanto, quando os fatores ambientais forem piores, maiores serão as possibilidades de que o organismo humano sofra alguma alteração ou que esteja propenso à ocorrência de acidentes de trabalho.

É preciso ter um conhecimento adequado das condições de trabalho, tanto dos fatores próprios da tarefa quanto daqueles que rodeiam o trabalhador, para que se possa realizar uma adequação nas condições do posto de trabalho analisado. Porém, existe uma relação estreita e direta entre condições de trabalho e conservação da saúde dos trabalhadores.

Muitas atividades e postos de trabalho apresentam riscos que devem ser analisados com o objetivo de conseguir sua minimização ou eliminação. A qualidade de vida que um indivíduo possa ter está intimamente ligada à qualidade do trabalho, às condições adequadas ou não em que ele desenvolve suas atividades.

O posto de trabalho dos operadores do caixa de supermercado é um exemplo da necessidade de mudanças devido aos riscos a que os trabalhadores estão expostos durante a realização das suas atividades. A intensidade em que o operador de caixa realiza seu trabalho é muito alta, não só pela quantidade e diversidade de tarefas que realiza, senão pela 
frequência, o que traz um aumento da carga mental e física dos trabalhadores.

A atividade dos operadores de caixas tem sido objeto de estudo devido ao grande número de queixas, moléstias ou transtornos. Entre outros, têm sido detectados transtornos do sistema músculoesquelético, dores de cabeça, transtornos do sono e do apetite, transtornos nervosos e fadiga visual (MTAS, s/d).

As atividades desenvolvidas pelos caixas de supermercados são intensas e altamente repetitivas, tornando-se ainda mais intensas pela introdução do scanner (INRS, s/d), que ajuda a diminuir o tempo de passagem de mercadorias, mas, diminui a atenção ao cliente. Esta alta repetitividade, unida a outros fatores próprios do trabalho, que serão analisados no presente artigo, leva ao aparecimento de monotonia no trabalho e ao estresse. Esta situação, quando unida às condições inadequadas do posto, às posturas e ao peso das mercadorias leva a um aumento das exigências físicas da atividade.
Quando existe uma adequada combinação entre as pausas, o revezamento de tarefas e a redução de trabalho se consegue uma diminuição da exposição aos fatores de risco. Ressalta-se que a alternância nos postos de trabalho objetiva a melhoria ergonômica das condições de trabalho (MAENO, M. et al., 1999; PEREIRA, R., s/d).

As posturas podem ser mais ou menos confortáveis ou prejudiciais para a saúde, dependendo fundamentalmente das condições de trabalho que tenha para realizar suas atividades. Um dos princípios fundamentais que devem existir em todo design ergonômico é que o mobiliário e suas relações com o ser humano permita, em primeiro lugar, que seja adaptado às características antropométricas da população que vai utilizar esse posto e que permita, quando necessário, as mudanças de posturas, já que em cada tipo de postura um diferente conjunto de musculatura é acionado.

Assegurar a postura para o trabalho na posição sentada e em pé, e as posições confortáveis dos membros superiores e inferiores, deve ser objetivo fundamental no design dos postos de trabalho dos operadores de checkout (BRASIL, 2007).

O operador de caixa de supermercados realiza mais funções além do estabelecido para esta atividade, em resumo: realizar a quantificação e o

Os caixas dos supermercados analisados atendem cerca de 300 clientes/dia, confirmando, então, a presença da repetitividade nas tarefas aliada a outras tarefas simultâneas, podendo gerar como consequência o desenvolvimento de problemas musculares e principalmente nas articulações das mãos, punhos, braços, ombros e vértebras cervicais (GARCÍA, J. P. et. al., 2003).

Sabe-se que quando não existe uma adequada combinação entre o trabalho físico e o intelectual e, por conseguinte, uma adequada organização do trabalho que garanta o estabelecimento de pausas de descanso, revezamento de atividade, etc. o indivíduo vai cada vez mais ao esgotamento mental e físico.

Para muitos autores o estabelecimento de pausas para o descanso, intercaladas no período de trabalho, é um elemento fundamental que permite a recuperação do indivíduo (VIÑA, S.; GREGORY, E., 1987).

Da mesma forma, se conhece por estudos realizados que uma sobrecarga de horas trabalhadas, ultrapassando as 8 horas recomendadas geralmente, leva a diminuição das reações e, consequentemente, a queda na produtividade, assim como danos pessoais, principalmente quando o trabalho é intenso (BLISS, J.; DUNN, M., 2000; GRANDJEAN, 1998; HARBER, P. et al., 1992; HINNEN, U. et al., 1992). pagamento das mercadorias que o cliente está comprando, representa aquela pessoa que mantém um contato direto e constante com os clientes, que de fato é assim. Muitas vezes são realizadas reclamações sobre o atendimento, que na maioria das vezes recaem nos operadores de caixa dos supermercados, como se fossem eles os culpados de uma determinada situação.

Todavia, recebem queixas de diferentes tipos, que podem ir desde um mau atendimento por parte dele, segundo o critério do cliente, até a falta de um determinado produto no mercado, mercadorias sem preço, demoras no sistema de pagamento por cartão, cheque, etc., algumas das quais não correspondem ao conteúdo de trabalho do posto e que não são de responsabilidade do operador de caixa de supermercado. Em resumo, pode-se dizer que a maioria das reclamações feita pelos consumidores passa pelos caixas, independentemente de eles possuírem ou não controle sobre o fato que está sendo reclamado.

Importante responder, o que pode ser realizado para garantir a minimização da situação estressante em que se encontra o operador de caixa de supermercado? Será que se tem pensado quanta é a responsabilidade e a carga de trabalho que esse operador tem durante todas as horas de trabalho?

A relação que deve existir entre a qualidade do serviço 
oferecido pelo operador de caixa e as condições de trabalho em que desenvolve suas atividades parece estar em contradição, cada vez mais o cliente demanda maior rapidez no serviço.

Por isso uma nova pergunta deve ser feita: será que é necessário realizar melhorias no posto de trabalho dos caixas de supermercado? Caso seja positiva a resposta, quais seriam estas modificações?

Estas e muitas outras perguntas podem ser feitas com o propósito de estudar, analisar e realizar recomendações para melhorar as condições de trabalho dos operadores de checkout de supermercados.

Cabe ressaltar que o objetivo deste trabalho foi identificar os fatores de risco a que estão expostos os operadores de caixa dos supermercados, assim como a análise das posturas realizadas pelos mesmos.

\section{MATERIAIS E MÉTODOS}

\subsection{População e amostra}

Foram estudados oito supermercados de duas cidades do Brasil com situações semelhantes quanto ao volume de vendas, quantidade de trabalhadores, etc., considerando-se quatro deles de mediano porte e quatro de pequeno porte. De uma população total de 82 trabalhadores, foram estudados 80 voluntários, totalizando $97,5 \%$ dos trabalhadores deste setor, cuja faixa etária está entre 18 e 41 anos, existindo uma prevalência de trabalhadores jovens, já que $91,25 \%$ (73) se encontram entre 18 e 30 anos, sendo a média de idade de 23,67 anos, e $83,75 \%$ (67) são do sexo feminino, como se mostra na Figura 1.

Quanto ao nível de escolaridade, 100\% dos trabalhadores pesquisados têm concluído pelo menos o ensino fundamental ( 8 anos terminados e aprovados). O tempo médio de trabalho na atividade é de 34,25 meses $(2,85)$ que para o tipo de trabalho repetitivo representa um tempo razoável para que o pessoal ganhe experiência na execução das atividades.

\subsection{Procedimentos de estudo}

Para conhecer os riscos a que estavam expostos os trabalhadores que pertencem à amostra, o estudo foi dividido em várias etapas.

Em uma primeira etapa os autores deste trabalho realizaram o processo de ambientação através da aplicação das técnicas da observação direta e da análise documental com o objetivo de conhecer a atividade que seria analisada.

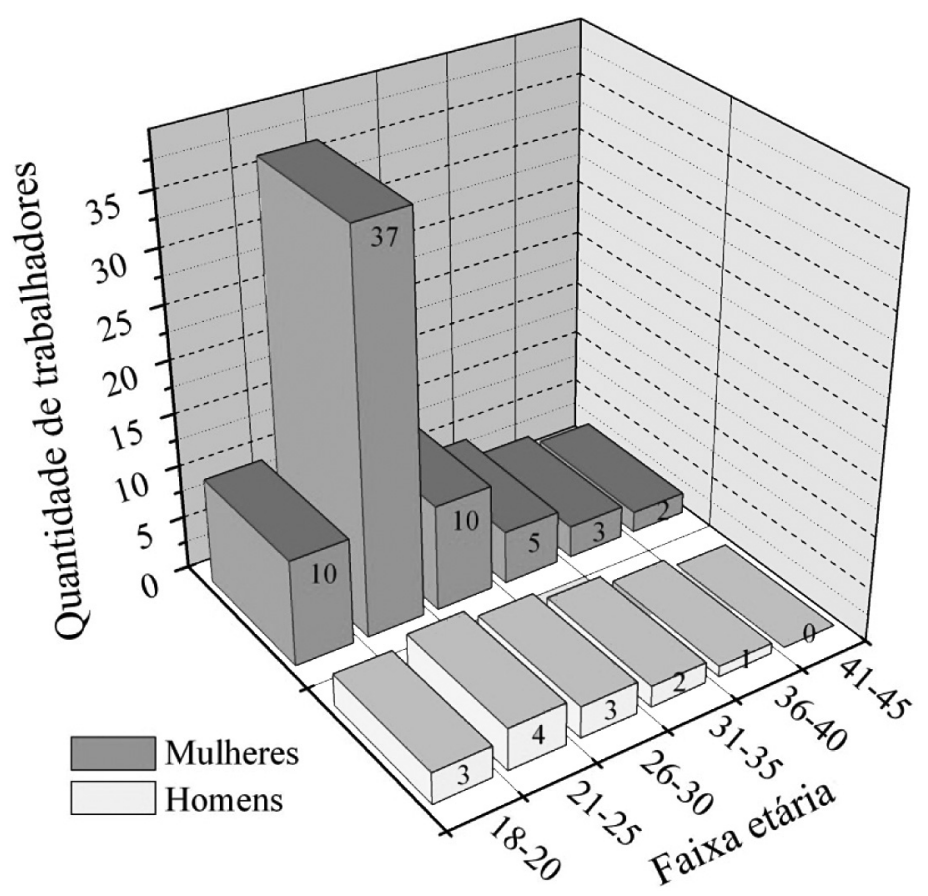

Figura 1: Distribuição da amostra por faixa etária e sexo. 
Determinou-se que as atividades realizadas pelos operadores de caixa nos supermercados analisados e o tempo em média gasto são:

1. Pegar o produto no início da bancada: esta atividade consiste em pegar a mercadoria deixada pelo cliente na esteira para posteriormente ser realizada a leitura óptica. A partir desta atividade o peso das mercadorias e as condições do posto de trabalho são determinantes na atividade. Geralmente o tempo que é investido nesta atividade está entre um e cinco segundos.

2. Transporte das mercadorias até o leitor óptico: consiste no traslado da mercadoria desde o lugar onde foi feita até o leitor óptico. O tempo está em média entre três e cinco segundos, dependendo da distância em que se encontra a mercadoria, do peso dela e de suas condições com relação à embalagem.

3. Leitura óptica: esta atividade consiste na passagem das mercadorias pelo leitor óptico. Esta atividade seria simples se os códigos de barras estivessem em condições adequadas para serem lidos pelo leitor. Em muitas ocasiões os códigos estão amassados, quebrados, molhados e precisam da realização de intervenções por parte do operador do caixa, que faz com que o tempo da atividade que normalmente está entre dois a cinco segundos seja aumentado até para mais de dez segundos, com o consequente carregamento da carga e realização de força nos membros superiores.

4. Digitação dos números dos códigos de barra, quando não lidos pelo leitor óptico. Quando é impossível que o leitor registre o produto, faz-se necessária a realização desta atividade. Em média demora entre cinco e quinze segundos, dependendo das condições de leitura dos números do código de barra.

5. Condução do produto registrado para a extremidade posterior da esteira. Esta atividade consiste em levar e depositar na esteira os produtos depois de passar pelo leitor óptico. Em média esta atividade demora entre um e cinco segundos.

6. Empacotamento. A atividade, que pode ser realizada quando todos os produtos passaram pelo leitor óptico ou quando existem muitos produtos a serem empacotados, dependendo do operador de caixa e das quantidades de mercadoria, apresenta como média de dez a vinte segundos por sacola. A atividade é dividida em três subatividades:

- pega da embalagem;

- abertura da embalagem;

- armazenamento do produto empacotado na extremidade final da bancada.

7. Manutenção da ordem e higienização do posto de trabalho. Esta atividade é realizada durante a passagem das mercadorias e/ou ao final da atenção ao cliente e, dependendo das condições em que fica o posto, pode demorar em média entre dez e vinte segundos.

8. Cobrança. Esta atividade poderá ter um maior ou menor gasto, dependendo da forma de pagamento do cliente e das condições de comunicação da rede, fundamentalmente quando se trabalha com cartões de crédito. Em média está entre vinte e quarenta segundos. Segundo a forma de pagamento esta atividade pode ser:

- passagem do cartão de crédito;

- passagem do cheque;

- pega do dinheiro e entrega do troco.

Em todos os casos, no final o operador de caixa entrega a nota fiscal ao cliente.

9. Outras atividades a serem realizadas pelos operadores de caixa:

- observação para que todos os produtos sejam registrados;

- troca de produtos a solicitação do cliente;

- entrega do dinheiro existente no caixa ao fiscal;

- solicitação de troco de dinheiro com outros caixas ou com o fiscal.

Depois de realizado o processo de ambientação, definiram-se as técnicas as quais foram aplicadas para conhecer e se aprofundar nos problemas existentes. As técnicas utilizadas foram a observação direta, questionário e entrevistas semi-estruturadas, estas últimas para completar as informações que seriam obtidas da aplicação do questionário.

A partir disso foi realizada a segunda etapa, que consistiu na elaboração de um questionário que foi dividido em cinco partes: a primeira parte relacionava os dados demográficos, buscando traçar o perfil do universo a ser estudado; a segunda parte tratava de questões ergonômicas e organizacionais do trabalho, objetivando conhecer individualmente as condições atuais de realização das atividades, considerando a aspectos técnicos (máquinas, leiaute, mobiliário), aspectos organizacionais (divisão do trabalho, o número e a duração das pausas, trabalho em turnos, ritmo de trabalho, etc.) e, ainda, os aspectos posturais; a terceira parte buscou avaliar as condições da cadeira com a finalidade de obter os dados relativos às condições favoráveis ou desfavoráveis aos usuários; a quarta parte abordou questões referentes às condições ambientais; e a quinta parte tratou da avaliação das condições físicas, objetivando identificar a origem dos possíveis problemas e os movimentos realizados.

Importante salientar que também constou de uma das etapas a aplicação do questionário a uma amostra controle (25 pessoas) com o objetivo de avaliá-lo e modificá-lo de acordo com as necessidades da presente pesquisa, para pos- 
teriormente ser aplicado à amostra selecionada.

Na seguinte etapa, a partir da aplicação de entrevistas e do questionário, detectaram-se os diferentes problemas apresentados pelos operadores de caixa em suas atividades.

A partir das queixas dos trabalhadores com relação às posturas inadequadas e às dores, optou-se por verificar com mais exatidão as posturas e movimentos executados pelos operadores durante a jornada de trabalho. Para isso foram realizadas filmagens e fotografias da atividade dos caixas, aplicando-se o método Rula (Rapid Upper Limb Assessment) sendo dividida as atividades do caixa em cinco etapas fundamentais: passagem da mercadoria pelo leitor óptico ou digitação dos números do código de barra, colocação das mercadorias no espaço posterior para empacotamento, empacotamento da mercadoria, atividade de cobrança ao cliente e limpeza da bancada.

Por fim, foram realizadas as análises dos resultados obtidos.

\section{RESULTADOS E DISCUSSÃO}

Mediante a aplicação do questionário, constatou-se que $100 \%$ dos operadores que participaram da pesquisa consideraram o trabalho altamente repetitivo, sendo que, destes,
$79 \%$ ainda o acharam cansativo, monótono e muito estressante, estando condizentes aos dados da pesquisa realizada por Ballardin (2005).

Quando estudadas as queixas do universo pesquisado, observa-se que $81 \%$ apresentam dores na região lombar, $54 \%$ apresentam dores nos ombros, 50\% apresentam dores na coluna dorsal e $49 \%$ no pescoço como sendo as regiões do corpo com maior incidência de dores. Observa-se igualmente que existem outras partes do corpo com dores que não deixam de ser significativas para as análises, independentemente de que as porcentagens de incidência sejam menores. As regiões com dores são condizentes com as obtidas na pesquisa realizada por Melo, A. da S. J. e Rodrigues, C. L. P. (2005). A Figura 2 apresenta os segmentos corporais mais afetados na amostra analisada.

De acordo com os dados acima mencionados, os autores acreditam que as queixas sejam de origem multifatorial, pois são vários os fatores que as predispõem, como as posturas e mobiliários inadequados e o manuseio repetitivo de produtos que às vezes são pesados, exigindo um esforço muscular ainda maior. O mesmo foi encontrado na pesquisa realizada por Battisti em que 95\% dos entrevistados relataram que a atividade é altamente repetitiva, sendo que pelo menos $65 \%$ sentem dor ou desconforto durante a jornada de trabalho (BATTISTI, H. et al., 2005).

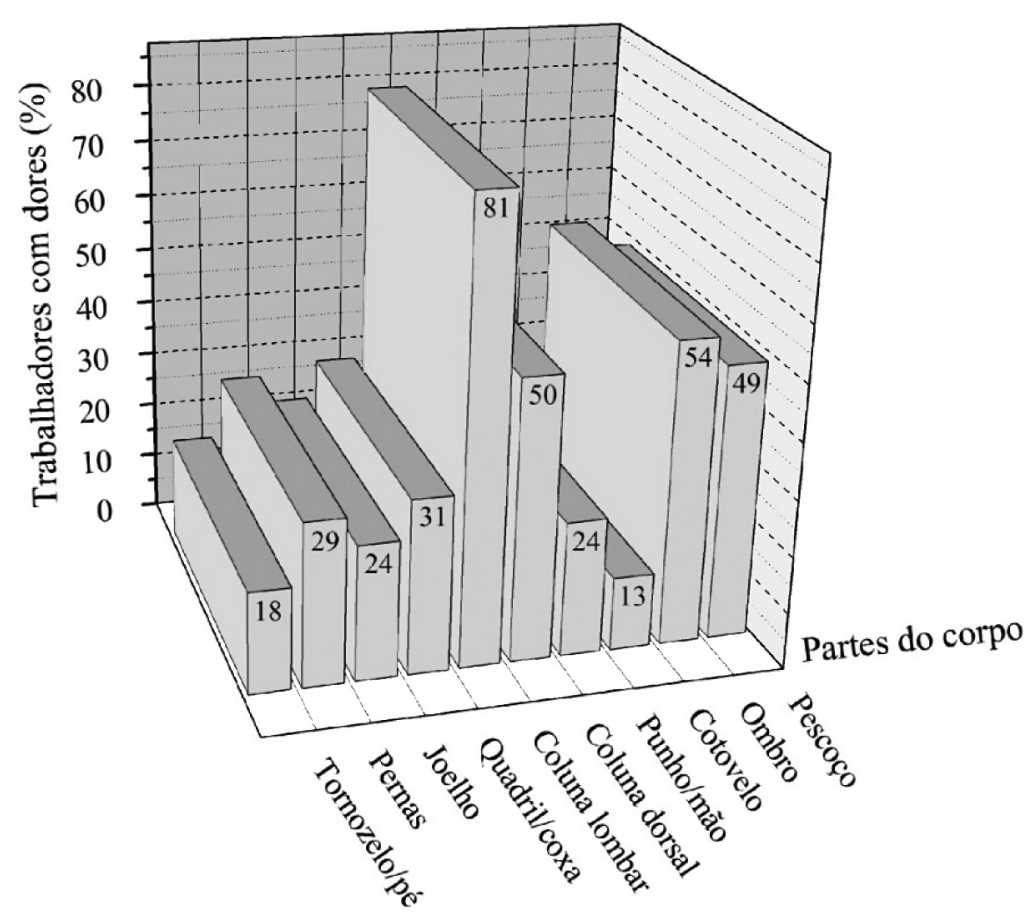

Figura 2: Segmentos corporais afetados. 
Trelha (2007) relata que os operadores exercem suas funções em postos de trabalho que possuem designs padronizados e, portanto, não levando em consideração as diferenças antropométricas individuais. $\mathrm{O}$ mesmo foi observado no presente estudo, quando analisadas as condições do posto de trabalho observou-se que $88 \%$ da amostra pesquisada (70 trabalhadores) consideram que o espaço interno do caixa é insuficiente e que, por conseguinte, não permite uma adequada movimentação, impossibilitando que ele possa mudar de posição com maior rapidez, já que quando movimenta a cadeira para trás pode incomodar o cliente do caixa ao lado.

As dimensões dos caixas pesquisados não correspondem às dimensões antropométricas sugeridas para a população que os utiliza, o que implica, entre outras coisas, na adoção de posturas inadequadas, que vão desde uma não correspondência entre a altura da bancada e a da cadeira, uma inadequada relação entre os dispositivos informativos a serem observados e a altura de visão dos trabalhadores, alcance máximo e mínimo frontal e lateral dos braços com relação à distância em que estão os produtos, onde devem ser deixados e onde devem ser passados. Estes dados assemelham-se aos achados por Ballardin (2005) em que as medidas do mobiliário eram incompatíveis entre os componentes do posto de trabalho.

\section{$\Lambda$ s dimensões do checkout não correspondem Aàs dimensões antropométricas da população que o utiliza.}

Da mesma forma ocorre com as cadeiras, não são adequadas às necessidades dos trabalhadores devido a não estarem adaptadas às dimensões do caixa, além disso, não possuem encosto ajustável, não oferecendo desta forma um suporte firme e adequado para a coluna lombar, o apoio para os pés não está em correspondência com a altura poplietal da população analisada, não permitindo apoio firme para os pés, fazendo com que os operadores fiquem com as pernas pendentes.

Com relação ao design do posto de trabalho, observou-se que não estava adaptado aos ângulos e áreas de visão dos trabalhadores, fazendo com que tenham que realizar constantes rotações e inclinações com o pescoço.

Trelha (2007) em seu estudo evidenciou que o trabalho era realizado na postura ortostática a maior parte do tempo, fazendo com que os trabalhadores adotassem cada vez mais posturas desequilibradas. Dados diferenciados foram encontrados na presente pesquisa, em que os trabalhadores permaneciam a maior parte do tempo na postura sentada, o que favorece a adoção de posições desfavoráveis que podem levar a desvios da coluna vertebral, além de provocar estase sanguínea nos membros inferiores, a qual pode ser agravada quando ocorrer compresão das coxas ou panturrilha contra a cadeira, fundamentalmente quando esta está mal posicionada, é mal desenhada ou não adaptada às características antropométricas da população.

Igualmente, quando o trabalhador permanece por longo período de tempo na postura em pé, existe uma tendência a que o sangue fique acumulado nas pernas, dificultando o retorno venoso, contribuindo para o surgimento de varizes, assim como dores nos joelhos, pernas, quadris. Quando o trabalhador, como é o caso dos caixas, mantém posturas inadequadas com os braços a posição em pé passa a ser mais cansativa e desgastante.

Muitas podem ser as razões que justifiquem a manutenção por determinado tempo da postura em pé, algumas das quais se ajustam perfeitamente às atividades do operador de caixa, como são a necessidade de manipular produtos cujo peso está acima de 4,5 kg e durante atividades de empacotamento. Qualquer tipo de investimento para garantir uma adequação ergonômica dos postos dos caixas será justificado quando comparados os efeitos fatigantes que traz ficar em pé por longos períodos de tempo.

Por tudo isto, os autores do presente artigo defendem o critério de que é preciso trabalhar para que os operadores de caixa tenham maior facilidade para realizar a alternância de posturas quando realmente seu corpo necessite, já que existe uma relação muito estreita entre os efeitos da postura e o tempo que ela será mantida, portanto, quanto maior o tempo que o caixa permanecer em uma mesma postura, maior será a possibilidade de ser afetado pelos efeitos nocivos desta.

Constatou-se que em muitas ocasiões são realizadas modificações no posto de trabalho sem considerar os princípios fundamentais da Ergonomia. Um exemplo observado durante a pesquisa foi o leitor óptico (LO) o qual foi adaptado ao caixa já existente, entretanto não foi realizada uma avaliação para um dimensionamento correto que permitisse aos operadores um maior conforto e segurança na realização das suas atividades.

O design do posto e, em alguns casos, a falta de equipamento como esteiras fazem com que o operador tenha que realizar inclinação ou rotações do tronco para poder manipular a mercadoria. Muitas vezes fazem com que ele tenha que se levantar da cadeira ou fazer movimentos rotacionais, flexão e extensão com o tronco, associados aos movimentos repetitivos com os membros superiores, que são ainda mais prejudiciais à saúde. 
Com o objetivo de conhecer melhor as posturas em que os operadores de caixa realizam suas atividades, foi aplicado o método Rula, sendo avaliadas 1.235 posturas considerando ambos os membros superiores nos oito supermercados encontrando-se resultados similares em todos eles.

Fazendo uma análise diferenciando o membro superior esquerdo do membro superior direito observa-se que: do total de posturas analisadas (Figura 3) considerando o membro direito se observa que $47,9 \%$ (592) das posturas encontram-se na categoria 2 , ou seja, que precisam ser tomadas mudanças em um futuro próximo; 22,0\% (272) das posturas encontram-se na categoria 3 , ou seja, que precisam de mudanças o mais breve possível; 10,4\% (128) das posturas encontram-se na categoria 4 , ou seja, que precisam de mudanças imediatamente e 19,7\% (243) das posturas e, por encontrarem-se na categoria 1 , não precisam de intervenção ergonômica. Quando analisadas as posturas considerando o membro superior esquerdo observa-se que $49,6 \%$ (612) das posturas encontram-se na categoria $2 ; 21,5 \%$ (266) das posturas encontram-se na categoria $3 ; 9,5 \%$ (117) das posturas encontram-se na categoria 4 e 19,4\% (240) das posturas encontram-se na categoria 1.

Em resumo, pode-se dizer que $80,3 \%$ das posturas analisadas considerando o membro superior direito e $80,6 \%$ considerando o membro superior esquerdo precisam de medidas ergonômicas que ajudem a melhorar as condições de trabalho.

Ainda sob análise das posturas, $19,7 \%$ e $19,4 \%$ a $25,4 \%$ das posturas que segundo o método Rula não precisam de intervenção ergonômica, se observa que muitas delas são iguais ou muito parecidas com outras que estão avaliadas com problemas. Isso se deve ao fato de que os pesos manipulados são menores ou iguais a $10 \mathrm{~kg}$ e isso tem uma influ-
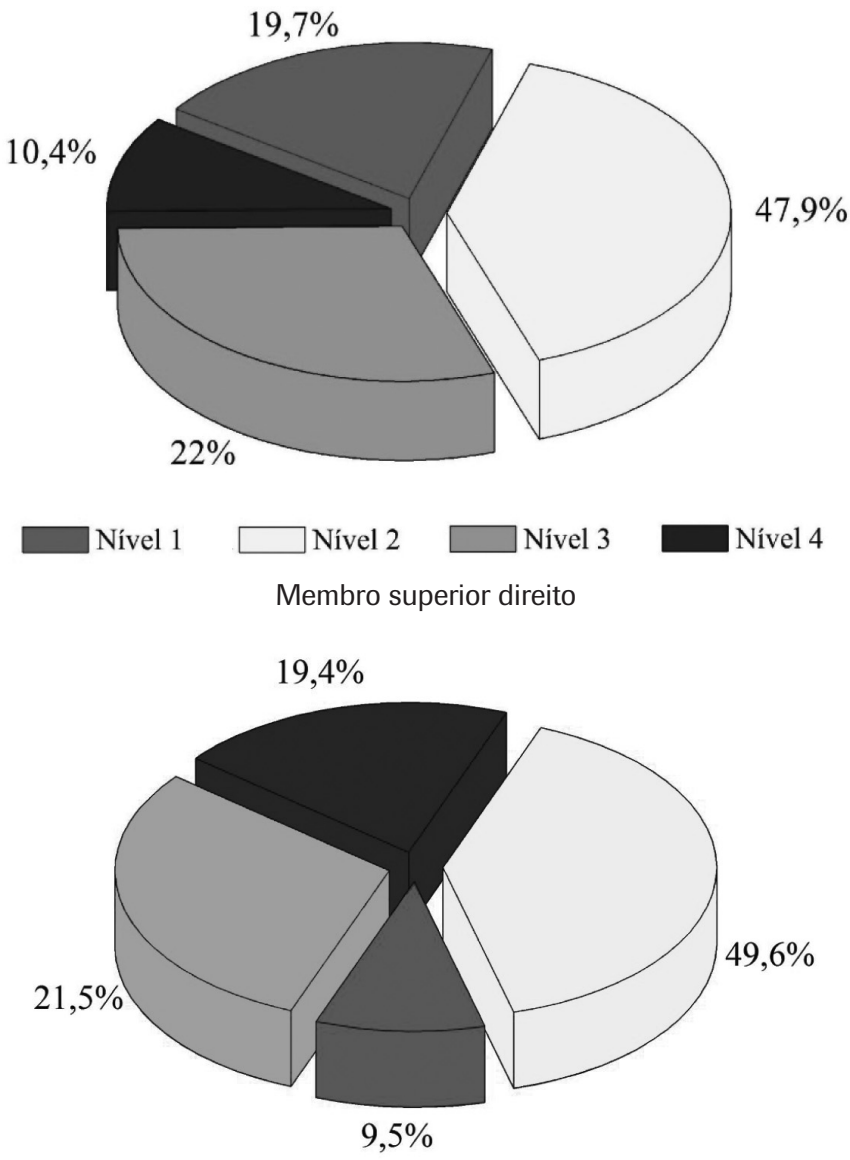

$\square$ Nível $1 \quad \square$ Nível 2 $\square$ Nível 3 $\square$ Nível 4
Membro superior esquerdo

Figura 3: Resultados da avaliação das posturas segundo o método Rula. 
ência fundamental na avaliação final, mas quando analisadas in loco, não deixam de ser posturas inadequadas. Uma parte importante da carga manipulada de forma repetitiva tem pesos iguais ou inferiores a $3 \mathrm{~kg}$, o que se pode traduzir em condições propícias para a ocorrência de patologias osteomusculares, que segundo Massambani (2002) tem se tornado um sério problema de saúde pública no Brasil, acrescendo ainda mais o problema com a economia.

Quando analisada a situação em cada uma das etapas em que foi dividida a atividade do caixa de supermercado observa-se que existem diferenças importantes entre cada uma delas com relação ao nível de avaliação que oferece o método Rula.

Na Tabela 1 observa-se como as piores posturas analisadas estão concentradas nas etapas de passagem da mercadoria pelo leitor óptico ou digitação dos números do código de barra, onde $30,1 \%$ do total de posturas analisadas nessa etapa correspondem ao nível 3 de avaliação e 17,3\% ao nível 4, ou seja, $47,4 \%$ das posturas, que segundo o método Rula precisariam urgentemente de medidas para melhorar a situação existente. Observa-se igualmente que só $10,3 \%$ das posturas analisadas nesta etapa não precisariam de medidas por não serem mantidas por longos períodos de tempo. Conforme a Figura 4, observa-se uma situação parecida quando analisadas as diferentes posturas do membro superior esquerdo.

Dos resultados anteriores se observa que as condições dos postos de trabalho são inadequadas, levando a adotar posturas que podem ser danosas ao organismo humano. Estes resultados são similares aos obtidos por Peres, et. al. (s/d), em que $50 \%$ dos postos analisados apresentam uma condição biomecânica ruim e 12,5\% péssima. Mais ainda, as posturas analisadas por eles com o auxílio do método
Rula mostram que todas se encontram no nível 4, ou seja, precisam com urgência medidas para melhorar os problemas detectados.

Todas estas situações influenciam diretamente a saúde dos trabalhadores e principalmente a produtividade da empresa, já que são causas que provocam afastamento do trabalho. $\mathrm{Na}$ amostra analisada constatou-se que $60,5 \%$ já foram afastados do trabalho por motivo de saúde pelo menos uma vez e que a causa fundamental foram as dores de origem músculoesquelética.

Da mesma forma, as condições atuais dos postos de trabalho são fontes de incidentes e acidentes do trabalho, que poderiam ser eliminados ou reduzidos se existisse uma ampla participação de todos os trabalhadores no processo de gestão de riscos. Na amostra analisada existe um alto índice de acidentes, já que $92,5 \%$ (74) dos trabalhadores sofreram algum tipo de acidente, sendo a causa fundamental, entre outras, a borda afiada da bancada, que quando em contato acidental com a mão ou o braço do trabalhador pode provocar ferimentos, assim como golpes provocados pela queda de mercadorias.

A duração da jornada de trabalho é um elemento fundamental para a conservação da saúde dos trabalhadores. Quando é muito extensa e intensa, é maior a possibilidade de aparição da fadiga, sendo necessária a introdução de pausas para descanso que garantam a recuperação do trabalhador. Quando estudada esta situação na amostra analisada observa-se que a jornada de trabalho está acima do limite permitido, que é de 44 horas semanais.

Em relação às horas trabalhadas, os caixas oficialmente trabalham 8 horas. Ressalte-se, porém, que de acordo com os depoimentos dos mesmos, geralmente permanecem

Tabela 1: Resultado da avaliação do método Rula considerando o membro superior direito em cada uma das etapas da atividade do caixa de supermercado.

\begin{tabular}{|c|c|c|c|c|c|c|c|c|c|}
\hline \multirow{3}{*}{ Etapa } & \multicolumn{8}{|c|}{ Níveis de avaliação segundo o Rula } & \multirow{3}{*}{ Total } \\
\hline & \multicolumn{2}{|c|}{ Nível 1} & \multicolumn{2}{|c|}{ Nível 2} & \multicolumn{2}{|c|}{ Nível 3} & \multicolumn{2}{|c|}{ Nível 4} & \\
\hline & Total & $\%$ & Total & $\%$ & Total & $\%$ & Total & $\%$ & \\
\hline $\begin{array}{l}\text { Passagem da mercadoria } \\
\text { pelo leitor óptico }\end{array}$ & 28 & 10,3 & 115 & 42,3 & 82 & 30,1 & 47 & 17,3 & 272 \\
\hline $\begin{array}{l}\text { Colocação mercadorias } \\
\text { para empacotamento }\end{array}$ & 35 & 15,0 & 119 & 51,1 & 64 & 27,5 & 15 & 6,4 & 233 \\
\hline $\begin{array}{l}\text { Empacotamento da } \\
\text { mercadoria }\end{array}$ & 72 & 22,6 & 170 & 53,3 & 58 & 18,2 & 19 & 5,9 & 319 \\
\hline Atividade de cobrança & 41 & 19,4 & 99 & 46,7 & 45 & 21,2 & 27 & 12,7 & 212 \\
\hline Limpeza da bancada & 67 & 33,7 & 89 & 44,7 & 23 & 11,6 & 20 & 10,0 & 199 \\
\hline Total & 243 & 19,7 & 592 & 47,9 & 272 & 22,0 & 128 & 10,4 & 1235 \\
\hline
\end{tabular}



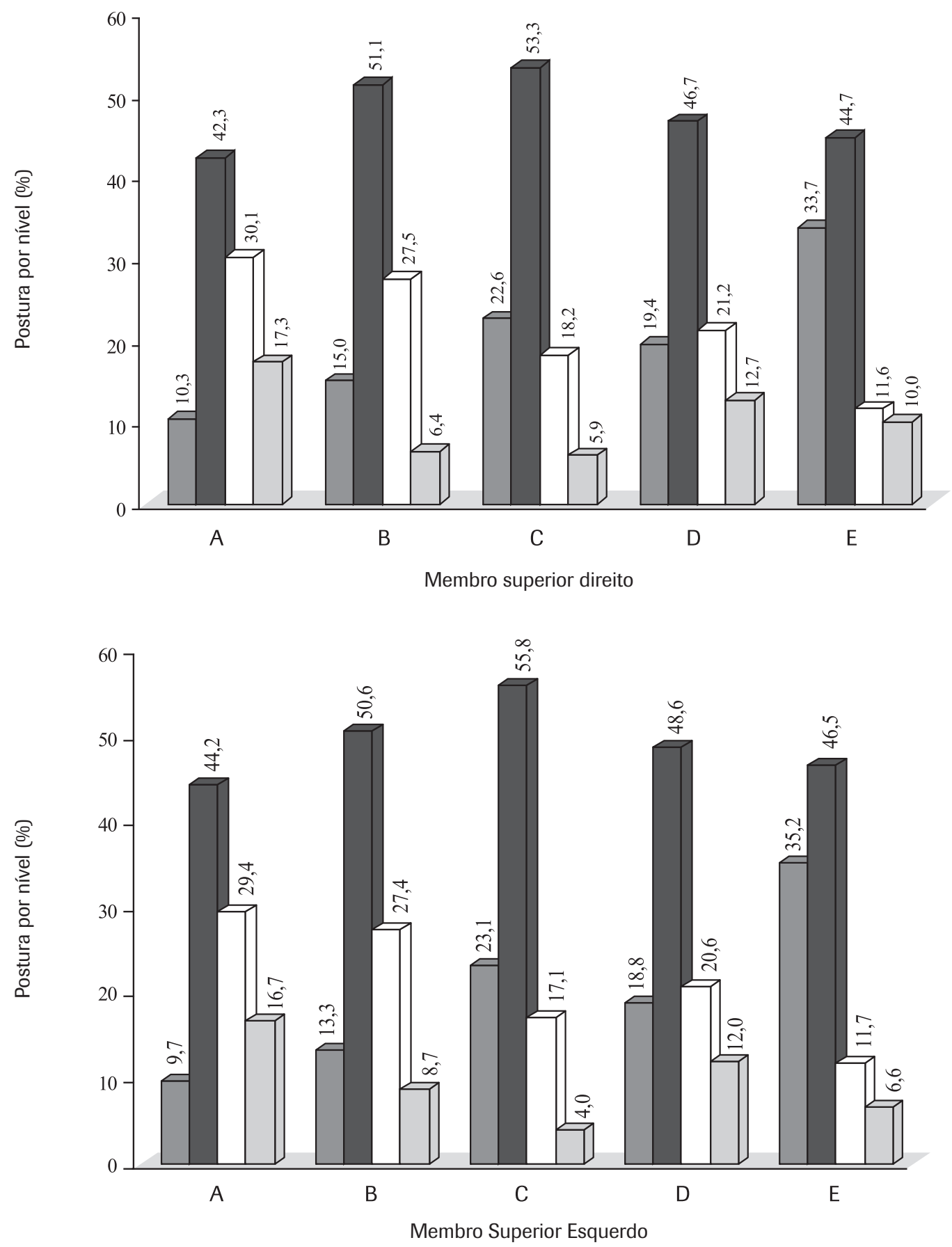

Legenda:

A - Passagem mercadorias pelo leitor óptico

B - Colocação de mercadorias para empacotamento

C - Empacotamento de mercadorias

Nível $1 \square$ Nível $2 \square$ Nível 3 $\square$ Nível 4

D - Cobrança

E - Limpeza da bancada

Figura 4: Resultado da avaliação do método Rula considerando tanto o membro superior direito quando o esquerdo em cada uma das etapas da atividade do caixa de supermercado. 
mais horas em serviço, em função da frequente presença de clientes ainda na fila do caixa após o encerramento normal do expediente, além da necessidade de realizar o fechamento do caixa; atividade que inclui, além de outras funções, a organização dos tickets e cheques. Observou-se que o tempo que o trabalhador permanece a mais após o fechamento do estabelecimento é de uma a duas horas em média, principalmente nos finais de semana.

Este elemento é de fundamental importância, devido a que as normas, métodos e análises estão baseados em 8 horas de trabalho por dia. Imagine-se a situação postural analisada anteriormente se o tempo de trabalho excede as 8 horas, sem dúvidas que seria muito mais prejudicial para os trabalhadores. Isso é apenas um exemplo, porque tal situação é válida para qualquer aspecto analisado na ergonomia, como é o caso do ruído, clima, iluminação, etc. Uma sobrecarga laboral com relação à quantidade de horas pode e de fato ocorre, ser uma via fundamental de incidentes e acidentes do trabalho, devido a diminuição da atenção ao trabalho, aumento do estresse, além de contribuir para uma diminuição da produtividade do trabalho. A este respeito, Ballardin (2005) complementa dizendo que as longas jornadas são motivo de reclamações apontadas pelas entidades do setor,

Quando questionados sobre a existência de pausas para descanso, constatou-se que 96,2\% dos entrevistados afirmaram não ter; eles têm apenas o horário de almoço e pequenos intervalos para idas ao banheiro. Segundo relato dos mesmos, após longo período de tempo na mesma postura e realizando a mesma atividade, e ainda sem ter pausas de descanso que permitam sua recuperação, ocorre uma diminuição do ritmo de trabalho ao sentir-se cansados.

Perante esta situação, observa-se o agravamento quando os trabalhadores, além de trabalhar mais de 8 horas por dia, como analisado anteriormente, realizam horas extras aos fins de semana e feriados, portanto, o total de horas trabalhadas por semana ultrapassa as 44 horas legisladas no país. Então chega-se a uma simples conclusão que são bem mais as horas de trabalho, e as possibilidades de descanso são muito menores.

Outro aspecto muito relacionado com o anterior e que permite além de diminuir a monotonia aumentar a produtividade de trabalho na realização de tarefas repetitivas é o revezamento de tarefas. No caso analisado não existe revezamento de tarefas, o que faz com que o trabalhador fique no posto durante toda a jornada de trabalho. O posto de o caixa de supermercado, que esta entre os postos mais exigentes quanto à repetitividade ou manutenção de posturas dinâmicas, quando não podem ser modificadas em curto prazo, devem ser ocupadas mediante rodízio de tarefas ou atividades diversificadas visando possibilitar diminuição aos fatores de risco aí presentes.

\section{CONCLUSÕES}

Ficou evidente no presente trabalho que a atividade analisada pode ser considerada de risco devido às condições em que é realizada:

- é altamente repetitiva, monótona e estressante, composta de uma alta carga física e mental;

- os horários de trabalho ultrapassam as horas estabelecidas para os trabalhadores, existindo igualmente um aumento das horas extras e, por conseguinte, menor descanso semanal para os operadores;

- não existem pausas para descanso que ajudem a recuperação da sobrecarga física e mental;

- as condições do mobiliário são totalmente inadequadas e não se adaptam às características antropométricas dos trabalhadores, implicando, entre outros aspectos negativos, constantes movimentos de rotação e inclinações do pescoço e do corpo desnecessários que aumentam a sobrecarga muscular nessas regiões;

- o espaço interno de trabalho é insuficiente;

- disposição inadequada dos dispositivos informativos e de controle e de outros utilizados durante o processo;

- as posturas e o peso a ser manuseado são responsáveis pelo grande número de trabalhadores com dores em diferentes partes do corpo.

Pode-se resumir que a atividade dos operadores de checkout precisa de uma intervenção ergonômica urgente, que inclui o design adequado do posto de trabalho, e de uma melhoria nas condições ambientais e organizacionais.

Assim, o estudo mostra que para compreender as condições em que os operadores de caixa de supermercados realizam suas atividades não basta avaliar os aspectos presentes na situação de trabalho isoladamente, sendo fundamental a investigação das condições como um todo, especialmente de como funciona a organização do trabalho. Desse modo, as implementações de mudanças, visando à melhoria das condições de trabalho, têm chance de tornar mais eficazes.

\section{Artigo recebido em 03/2007 Aprovado para publicação em 12/2008}




\section{REFERÊNCIAS}

BALLARDIN, L.; FONTOURA, C.; FELLIPPA, C. S.; VOGT, M. S. Análise Ergonômica dos Postos de Trabalho de Operadores de Caixas de Supermercados. Revista Produção, v. 5, n. 3, 2005.

BATTISTI, H. H.; GUIMARÃES, A. C. A; SIMAS, J. P. N. Atividade Física e Qualidade de Vida de Operadores de Caixa de Supermercado. Ver. Brasileira Ciência e Movimento, v. 13, n. 1, 2005.

BLISS, J. P.; DUNN, M. C. Behavioral implications of alarm mistrust as a function of task workload. Ergonomics, v. 43, n. 9, 2000.

BRASIL. Ministério do Trabalho e Emprego. Portaria SIT n. 08, de 30 de março de 2007. Aprova o Anexo I da NR-17 - Trabalho dos Operadores de Checkout. Diário Oficial da República Federativa do Brasil, Brasília, DF, 02 abril 2007. Disponível em: $<$ http://www.mte.gov.br/legislacao/normas regulamentadoras/nr_17_anexo1.pdP. Acesso em: 05 mar. 2008.

DEJOURS, C. A Loucura do Trabalho: estudo de psicopatologia do trabalho. 4. ed. São Paulo: Cortez, 1991.

GARCÍA, J. P.; PARADA, R. L.; GUTIÉRREZ, R. C. Lesiones músculo-esqueléticas de espalda, columna vertebral y extremidades y su incidencia en la mujer trabajadora. Cajeros/as de supermercado. Guía Informativa para el uso de trabajadores/as y delegados/as de prevención. Instituto Canario de Seguridad Laboral. Islas Canarias, octubre de 2003.
GRANDJEAN, E. Manual de ergonomia: adaptando o trabalho ao homem. 4. ed. Porto Alegre: Bookman, 1998.

HARBER, P.; PEÑA, L.; BLAND, G.; BECK, J. Upper extremity symptoms in supermarket workers. American Journal of Industrial Medicine. 22. 1992.

HINNEN, U.; LAUBLI, T.; GUGGENBUHL, U.; KRUEGER, H. Design of check-out systems including laser scanners for sitting work posture. Scand J Work Environ Health, 1992.

INSTITUTO NACIONAL DE PESQUISAS EM SEGURANÇA (INRS). Las "Hiper" Cajeras. Publicado em: www.ergonomia.cl/cajeras.doc. Acesso em: 25 jul. 2006, s/d.

MAENO, M.; ALMEIDA, I. M.; MARTINS, M.; TOLEDO, L. F.; PAPARELLI, R. Diagnóstico, tratamento, reabilitação, prevenção e fisiologia das LER/DORT. 1999.

MASSAMBANI, E. M. Incidência de Distúrbios músculo-esqueléticos entre farmacêuticos-bioquímicos e suas repercussões sobre a Qualidade de Vida e de Trabalho. Dissertação de Mestrado em Ergonomia. UFSC. 2002.

MELO, A. da S. J.; RODRIGUES, C. L. P. Avaliação de estresse e dor nos membros superiores em operadores de caixa de supermercado na cidade de João Pessoa: estudo de caso. Anais do XXV ENEGEP. Porto Alegre, Brasil, 2005.
MINISTÉRIO DE TRABAJO E ASUNTOS SOCIALES - MTAS. Guía metodológica para el estudio ergonómico del trabajo de cajera de hipermercado. Instituto Nacional de Seguridad e Higiene en el Trabajo. Em: www.mtas.es/insht/ practice/g_cajeras.htm. Acceso em: 05- mar. 2008. Espanha, s/d.

MONTMOLLIN, M. A ergonomia. Tradução: Joaquim Nogueira Gil. Sociedade e Organizações, 1997.

PEREIRA. R, E. Fundamentos de ergonomia e fisioterapia do trabalho. São Paulo, s/d.

PERES, C. C.; BORGES, J. E. S.; SILVEIRA, M. M.; OLIVEIRA, P. A. B de; LIMA, V. A. Multiprofissionalidade e interinstitucionalidade necessárias em uma ação ergonômica complexa. Em: http://www.ergonet.com.br/download/ amultiprofissionalidade-claudio_c_peres.pdf. Acessado: 07-03-2008. Brasil, s/d.

SELL, I. Qualidade de vida e condições de trabalho. In: Medicina básica do trabalho. Curitiba: Gênesis, v. 5, p.158-175, 1995.

TRELHA, C. S.; CARREGARO, R. L.; CASTRO, R. F. D.; CITADINI, J. M.; GALLO, D. L. L.; SILVA, D. W. Análise de Posturas e Movimentos de Operadores de Checkout de Supermercado. Ver. Fisioterapia em Movimento, v. 20, n. 1, 2007.

VIÑA, S.; GREGORY E. Ergonomía. La Habana: Editora Pueblo y Educación, 1990.

WISNER, A. A inteligência no trabalho: textos selecionados de ergonomia. Trad. Roberto Leal Ferreira. São Paulo: FUNDACENTRO, 1994.

\section{SOBRE OS AUTORES}

\section{Eduardo Concepción Batiz}

Sociedade Educacional de Santa Catarina (SOCIESC) - Instituto Superior Tupy (IST)

End.: Joinville - Santa Catarina - Brasil

Tel.: 55 (47) 3461-0277

E-mail: eduardo.batiz@sociesc.org.br

Andréia Fuentes dos Santos

Universidade Paranaense (UNIPAR)

End.: Umuarama - Paraná - Brasil

Tel.: 55 (44) 3622-7088

E-mail: fuentesfisio@hotmail.com

\section{Olga Elena Anzardo Licea}

Tel.: 55 (47) 3433-3454

E-mail: oanzardo@yahoo.com.br 